\title{
Mekânın Temsili: \\ Uzamsal Düşüncenin Zihinsel Döndürme Performansına Etkisi
}

\author{
A. Reyyan Bilge ${ }^{1}$ \\ İstanbul Şehir Üniversitesi \\ İstanbul Medipol Üniversitesi
}

\begin{abstract}
Özet
Hayatımızın her alanında yer alan uzamsal/mekânsal bilginin işleyiş ve kullanımında bireysel farklılıklar gözlenir. Bu çalışmayla, cinsiyet değişkeni sabit tutularak uzamsal düşünce tarzı ve uzamsal yetenek arasındaki ilişkiye odaklanılmıştır. Alan yazında sıklıkla raporlanan cinsiyet faktörünün, uzamsal performanstaki bireysel farklılıkları açıklayıcı tek faktör olmadığı, mekânın zihinsel temsili gibi başka faktörlerin de bu durumu etkileyeceği yordanmıştır. Çalışmanın örneklemi hepsi kadın, 61 üniversite öğrencisinden oluşmaktadır. Uzamsal düşünce tarzı öz-bildirime dayalı ölçeklerle, uzamsal yetenek ise alan yazında yaygın olarak kullanılan Zihinsel Döndürme (ZD) testiyle ölçülmüştür. ZD görevindeki farklı strateji kullanımını sağlayabilmek adına 3 boyutlu uyaranlar hem bütün hem de kesik şeklinde sunulmuş, ardından Uzamsal Temsil Anketi ve Santa Barbara Yön Duyusu Ölçeği verilmiştir. Öz-bildirime dayalı ölçek skorlarına göre, katılımcıların bir mekânı zihinlerinde temsil ediş tarzları (kuşbakışı veya işaret) belirlenmiştir. Araştırmanın sonucunda, ZD testinin temel bulgusu olan Açı Farkı etkisi görülmüş; uyaran çiftleri arasındaki açı farkı arttıkça tepki zamanı yavaşlamış, doğruluk oranı azalmıştır. Ayrıca, Uyaran Şekli ve Uzamsal Temsilin ZD performansını etkilediği bulunmuştur. Açı farkı arttıkça, yani görev zorlaştıkça, kuşbakışı temsil oluşturanlar, işaret temsili yapanlara nazaran figürleri zihinlerinde daha hızlı döndürebilmişlerdir. Aynı tepki örüntüsü, Uyaran Şekli için de gözlenmiş; figürler arasındaki açı farkı azken kesik, fazlalaşınca bütün şeklindeki uyaranlar daha doğru döndürülmüştür. Önceki bulguları destekleyen bu çalışma, mekânsal biliş ve uzamsal yetenek farklarının sadece cinsiyet faktörüyle açıklanamayacağını, uzamsal düşünce tarzı gibi faktörlerin de önemli bir rol oynadığını önermektedir.
\end{abstract}

Anahtar kelimeler: Uzamsal biliş, mekânsal temsil, uzamsal zihinsel modeller, zihinsel döndürme, bireysel farklılıklar

\begin{abstract}
Individual differences are observed in processing and usage of spatial information in all areas of our lives. This study focuses on the relationship between spatial thinking style and spatial ability by holding gender constant. Gender, frequently reported in the literature, was predicted not to be the only factor explaining individual differences but there are other factors such as spatial representation. The sample consisted of all women, 61 university students. Spatial thinking style was measured by self-report questionnaires and spatial ability by Mental Rotation (MR) test. To enable the use of different strategies, 3D stimuli were presented in whole and cut form, followed by the Spatial Representation Questionnaire and the Santa Barbara Sense of Direction Scale. Participants were categorized according to the way they represented space in their minds (survey or landmark). The main finding of the MR literature, Angular Disparity Effect, was replicated; as the angular disparity between the stimuli pair increased, response time slowed down and the accuracy ratio decreased. Furthermore, the stimulus shape and spatial representation were found to influence MR performance. As the angular disparity increased, so did the complexity of the task, and participants, who formed survey representations rotated the figures than the ones with landmark representations. Same pattern was observed with stimulus shape; as angular disparity increased, whole figures were rotated faster. Supporting the previous findings, current study suggests that differences in spatial cognition and spatial skills cannot solely be explained by gender but other factors such as spatial thinking style play an important part.
\end{abstract}

Keywords: Spatial cognition, spatial representation, spatial mental models, mental rotation, individual differences

Yazışma Adresi: 'Dr. Öğr. Üyesi, A. Reyyan Bilge, Medipol Üniversitesi, İnsan ve Toplum Bilimleri Fakültesi, Psikoloji Bölümü, Kavacık Güney Yerleşkesi, Göztepe Mah. Atatürk Cad. No: 40 / 16, 34815 Beykoz / İstanbul, reyyan.bilge@medipol.edu.tr, ORC-ID: 0000-0003-2105-0122 Gönderim Tarihi: 04.07.2019

Kabul Tarihi: 24.10 .2019 
Günlük hayatta kullanılan bilgilerin çoğu uzamsaldır yani mekâna dair bilgi içerir. Uzamsal/ mekânsal biliş (spatial cognition) ise tüm zihinsel süreçlerin yer ve mekân bilgisiyle harmanlanmasıdır. Uzayda kapladığımız alanı ve nerede konumlandığımızı kavramaya çalışır, kendimizle beraber çevremizdeki küçük ve büyük ölçekli nesnelerin, binaların, vb. mekân bilgisini işleriz. Oldukça sıradan gözüken birçok aktivitenin temelinde uzamsal bilgilerin işlenmesi yatar. Örneğin, bulunduğunuz yerden güney, kuzey, batı ve doğu yönlerini göstermek, evden işe gidiş yolunu tarif etmek, hatta saat okumak gibi ikincil addedilen görevler dahi uzamsal bilişsel mekanizmaları kullanır. Mekâna dair bilgiler sürekli işlenip kullanılmasına rağmen, uzamsal işleyişte bireysel farklılıklar, özellikle de cinsiyete bağlı performans farklar1 (Collins ve Kimura, 1997; Linn ve Petersen, 1985) gözlenmektedir. Bu çalışmayla; uzamsal/ mekânsal bilginin gerek küçük gerekse büyük ölçekte nasıl işlendiği ve kullanıldığ 1 araştırılmış ve salt kadınlardan oluşan bir örneklemle, cinsiyetin uzamsal performans farkını açıklayıcı tek faktör olmadığı, mekânın zihinsel temsili gibi başka faktörlerin de bu durumu etkileyeceği yordanmıştır.

\section{Mekânın Zihinsel Temsili ve Uzamsal Düşünce Tarzı}

Mekânın zihinsel temsili, yani herhangi bir nesneyi ya da yeri düşündüğümüzde zihinde canlanan imge, bir referans çerçevesi (reference framework) dahilinde oluşturulur (Taylor ve Tversky, 1996). Uzayda yer kaplayan bir nokta, koordinat sistemine yerleştirilir. Bakış açısı ve referans noktas1, koordinat sisteminin merkezine neyin konumlandırıldığına göre değişir. Merkeze bir nesne yerleştirilmesi durumunda, uzamsal bilgi A ile B'nin birbiriyle ilişkisi, yani nesne-nesne ilişkisi (alosentrik; allocentric) üzerinden kodlanır, temsil edilir ve ileride kullanılmak üzere saklanır (Easton ve Sholl, 1995). Alosentrik temsil, büyük ölçek bazında binaları, mahalleleri ya da şehirleri birbirleriyle ilişkilendirme üzerinden oluşur. $\mathrm{Bu}$ temsilde, yön bilgileri (örn; kuzey, batı) nesne-nesne ilişkilerini tanımlarken kullanılır. Referans çerçevesini bir de egosentrik çizilebilir. Egosentrik yani benmerkezci çerçevede ise kişinin kendisi koordinat sisteminin merkezidir ve uzamsal bilgi, kişi-nesne arasındaki ilişki üzerinden temsil edilir. Herhangi bir mekân algılanırken, kodlanırken, saklanırken ve tarif edilirken kişi kendine referans verir (örn: sağım, solum). Böylece zihindeki temsillerin gerektiğinde kullanılabilmesi için mekânsal/ uzamsal zihin modeller oluşur (Easton ve Sholl, 1995; Taylor ve Tversky, 1996). Bu modeller her zaman aynı olmamakla beraber, mekânın büyüklüğüne ve öğreniliş tarzına göre de şekillenir.

İnsanların mekâna dair düşünce tarzları (uzamsal düşünce tarzı), bir bilgi işleme yoludur. Bilinen bir mekân hakkında düşünürken, örneğin, ev-iş arasındaki yolu zihinde canlandırırken, bazı kişiler yukarıdan kuşbakışı görüyormuşçasına bir düşünme tarzını tercih eder (kuşbakışı perspektif), bazıları belirli bir rota üzerinde hareket ediyormuşçasına ilerlediklerini hayal eder (rota perspektifi), bazıları ise anıtlar, okullar veya marketler gibi işaretleyici noktalar üzerinden düşünmeyi tercih eder (işaret perspektifi) (Easton ve Sholl, 1995). Kısacası, mekânın zihinsel temsili ile düşünce tarzı arasında paralellikler vardır. Zihinde oluşan bu temsillerin altında yatan neden tam olarak bilinmemekle beraber uzamsal süreçleri etkilediği bilinmektedir.

Çevremizde bulunan, büyük ölçekteki mekânsal bilgiyi işleyiş tarzımız farklılaşabilir. Alosentrik bakış açısıyla öğrenilen ya da kullanılan mekânsal bilginin, zihinde kuşbakışı temsil edilmesi, egosentrik bakış açısıyla öğrenilen veya kullanılan bilginin ise işaretleyici noktalar üzerinden temsil edilmesi doğaldır. Önceki çalışmalarda, kişinin büyük ölçekteki bir mekânı (örn., ilk defa gittiği bir şehir) düşünürken, kuşbakışı veya işaret perspektiflerinden ağırlıklı olarak hangisini kullandığına bakılmış (Bilge ve Taylor, 2017; Pazzaglia ve De Beni, 2006), bunun uzamsal testlerdeki performansa etki ettiği öne sürülmüştür (Bilge ve Taylor, 2017). Burada dikkat edilmesi gereken nokta; büyük ölçekteki mekânı düşünürken, bu bilgiyi zihninde canlandırırken veya mekânın içinde hareket ederken, kişi dikotomik olarak kuşbakış1 veya işaret temsili kullanmaz ama ağırlıklı olarak bunlardan birini tercih edebilir veya bir düşünüş tarzına daha yatkın olabilir. Kullanılan ölçeklerin amacı da uzamsal düşüncedeki yatkınlığı ve farkları ortaya koyabilmektir (Pazzaglia ve De Beni, 2006).

Çevresindeki alan içinde hareket ederek ya da haritadan bakarak konumların kendisiyle ve birbirleriyle ilişkilerini anlayabilmek mekân bilgisinin büyük ölçekte, daha global olarak işlenmesidir. Nesne-içi veya nesneler arası ilişkileri anlayabilme, kişinin zihninde bu figürleri eğip büküp çevirebilmesi ise uzamsal bilginin küçük ölçekte, daha lokal olarak işlenmesidir. Uzamsal biliş konusunda, her iki işleyişte (ölçekte) de bireysel farklılıklar rapor edilmektedir.

\section{Uzamsal / Mekânsal Bilişte Bireysel Farklılıklar}

Küçük ölçekteki uzamsal bilgiyi ölçmek, uzamsal yetenek testleri ile mümkündür. Çoklu zekâ teorisinin (Carroll, 1993) içinde de yer alan uzamsal yetenek, etrafımızı anlayabilme ve çevremizi anlamlandırabilme konularında uzamsal bilgiyi ne kadar iyi işlediğimizle ilgilidir. Uzamsal yetenek; tasarlanmış görsel imgeleri oluşturmak, zihinde tutmak, anımsamak ve dönüştürmek olarak tanımlanabileceği gibi (Lohman, 1996), evrendeki nesnelerin zihinsel görsellerini oluşturmak, bunları farklı şekillerde tanımlamak ve bu nesneleri 
bir bütün ya da parçalar halinde hareket ettirmek gibi becerilerin birleşimi olarak da nitelenebilir (Alkan ve Erdem, 2011). Alan yazında uzamsal yetenek; uzamsal ilişkiler ve uzamsal görselleştirme diye tanımlanan iki bileşenden oluşur (McGee, 1979; Pellegrino, Alderton ve Shute,1984). Bazı araştırmacılar da uzamsal yeteneği uzamsal görselleştirme ve zihinsel döndürme (bkz. Hegarty, 2018; Hegarty ve Waller, 2004; McGee, 1979) olarak ayırır. Standardize edilmiş uzamsal yetenek testlerinde, uzamsal ilişkiler iki boyutlu ve üç boyutlu döndürmeleri ve küp karşılaştırmalarını içerir. Alanda sıklıkla kullanılan Zihinsel Döndürme (Mental Rotation) (Shepard ve Metzler, 1971; Vandenberg ve Kuse, 1978) testi buna örnektir. Uzamsal görselleştirme ise, üç boyutlu alanda nesnelerin dönüşümlerini ve bazı k1sımlarını katlamayı veya açmayı hayal edebilme yeteneği olarak tanımlanır (McGee, 1979). Minnesota Kağıt Form Kartı (Likert ve Quasha, 1969), Kağıt Katlama Testi (Ekstrom, French, Harman ve Dermen, 1976) gibi testler de görselleştirmeye örnektir. Tanımlardan anlaşıldığı gibi, her iki faktör de görsel imgelerin zihinsel manipülasyonunu içerir. Bu araştırmada küçük ölçekteki uzamsal bilişi ölçmek için, özellikle, alan yazındaki cinsiyet farkını ortaya çıkaran bir uzamsal ilişki testi kullanılmıştır.

Zihinsel Döndürme (ZD); uzamsal becerileri ölçmek için sıkça kullanılan bir testtir. ZD testi sırasında şekiller zihinde döndürülürken birkaç aşamadan geçer (Cooper ve Shepard, 1973; Gardony, Taylor ve Brunye, 2014; Just ve Carpenter, 1976). İlk olarak, kişiye sunulan iki uyaran da kodlanır. Bir tanesi diğeriyle aynı hizaya gelecek şekilde döndürülür. İki şekil aynı hizada olunca, katılımcı figürleri karşılaştırır ve aynı olup olmadıklarına karar verip cevaplandırır. Açı farkı ve yanıt ilişkisini gösteren regresyon verileri farklı ZD aşamasını gösterir (Kail, Carter ve Pellegrino, 1979): eğim, zihinsel dönüşüm hızını ve kesişim de kodlama, karşılaştırma ve yanıt süreçlerini yansıtır. Göz hareketlerini rapor eden çalışmalar da bu aşamaları önermektedir (Freedman ve Rovegno, 1981; Tarr ve Pinker, 1990).

ZD testinde, katılımcıya sunulan iki figürün arasındaki derece farkıyla döndürme zamanı arasında pozitif (Shepard ve Metzler, 1971), derece farkıyla cevapların doğruluğu arasında negatif korelasyon vardır (Butler vd., 2006). Bu olguya da Açı Farkı Etkisi (AFE) denir. AFE kağıt-kalemle yapılan ZD testlerinde de (Collins ve Kimura, 1997; Vandenberg ve Kuse, 1978) bilgisayarla yapılanlarda da (Voyer ve Bryden, 1990) bulunmuştur. Katılımcıların bir figürü diğeriyle örtüşecek kadar döndürdükleri öne sürülmüş olsa da son senelerde elde edilen bulgulara göre zihinsel döndürme birebir örtüşme değil, sonuca götürecek kadar yakınlaştırmayla olmaktadir (Gardony vd., 2014).
ZD testi ilk oluşturulduğu zamandan beri (Shepard ve Metzler, 1971) çeşitli alanlarda kullanılmaktadır. Son senelerde de gelişimsel psikoloji (Hahn, Jansen ve Heil, 2010; Quinn ve Liben, 2014), insan faktörleri mühendisliği (Kadam ve Iyer, 2014; Parsons, Courtney, Dawson, Rizzo ve Arizmendi, 2013), eğitim (Uttal ve Cohen, 2012), klinik psikoloji (Pearson, Deeprose, Wallace-Hadrill, Heyes ve Holmes, 2013), ekonomi (Lippa, Collaer ve Peters, 2010) ve bilişsel mekanizmalar (Neubauer, Bergner ve Schatz, 2010; Moreau, 2012) alanlarında kullanılmış ve cinsiyet farkının en net gözlemlendiği ölçeklerden birisi olagelmiştir. Erkeklerin figürleri zihinlerinde hem daha hızlı (Kail vd., 1979) hem de daha doğru bir şekilde (Collins ve Kimura, 1997) döndürdügü bulunmuştur. Meta-analizler de erkeklerin ZD konusunda çok daha iyi olduklarını göstermektedir (Linn ve Petersen, 1985; Voyer, Voyer ve Bryden, 1995; Voyer, Voyer ve Saint-Aubin, 2017). Fakat uzamsal bilgi sadece nesneler arasındaki ilişkiyi değil, geniş ölçekteki mekân bilgisini de içerir.

Mekâna dair bilgiyi, temsil etme ve kullanma konularında da kadın-erkek arasında farklılıklar var. Navigasyon ve yol bulma, zihinsel veya davranışsal olarak nerede olduğumuzu bilme ve belirli varış hedeflerini bulmayı gerektirir (Passini, 1984). Kadınlar herhangi bir mekânı tarif ederken genelde işaretleyici noktaları (landmark) esas alırken (örn.; bakkaldan sağa) erkekler çoğunlukla metrik birimleri (örn.; 100 metre sonra) ya da kardinal yönleri (örn.; kuzey, güney) kullanır (Lawton, 2010). Coluccia ve Louse (2004), yol bulma becerilerinde (örn, koşarak hedef bulma, işaretleme, uzaklık tahmini, stratejiye dayalı yol bulma, bilgisayarlı labirent öğrenme, video kayıtlarına dayalı rota öğrenme) cinsiyet farkl1lıklarını değerlendirmiş, çalışmaların en az \%53'ünde önemli bir erkek avantajının olduğunu, \%12'sinde kadın avantajının ortaya çıktığını belirlemişlerdir. Zihinsel yön belirleme (orientation) görevlerinde de erkeklerin kadınlardan daha iyi performans gösterdikleri belirtilir (Linn ve Petersen, 1985; Maeda ve Yoon, 2013; Voyer vd., 1995). Erkeklerin harita okumada (Dabbs, Chang, Strong ve Milun, 1998; Lawton, 2010), kadınların ise uzamsal bellek konusunda daha avantajlı olduğu görülmüştür (Eals ve Silverman,1994; Tottenham, Saucier, Elias ve Guntwin, 2003). Erkek-kadın farkının kadın lehine olduğunu bulan araştırmalar olmakla beraber (Choi vd., 2016), navigasyonda bir yol ya da rota öğrenirken kadın-erkek arasında anlamlı fark bulmayan araştırmalar da vardır (Golledge, Ruggles, Pellegrino ve Gale, 1993). Kısacası, mekâna dair bilginin kullanımındaki farklılıklar bu tür becerilerin kişiden kişiye değiştiğini göstermektedir. Bu da bilgiyi sürekli işlememize rağmen bazılarının mekânı algılama konusunda etkin yöntemler ya da stratejiler kullandığına işaret eder. 


\section{Uzamsal / Mekânsal Performans Farkının Nedenleri}

Gerek küçük ölçekte gerek de büyük ölçekte uzamsal ve mekânsal biliş farklılıkları, özellikle de cinsiyet farkları bulan araştırmalar göz önüne alındığında, etkili olan faktörler arasında; kullanılan strateji (Bilge ve Taylor, 2017; Hegarty, 2018), hormonel değişimler (Driscoll, Hamilton, Yeo, Brooks ve Sutherland, 2005; Hausmann, Slabbekoorn, Van Goozen, Cohen-Kettenis ve Güntürkün, 2000; Kurt, Bekci ve Karakas, 2004), beyin yapıs1 (Arpac1, 2009; Kandemir, Örnek ve Kırbaş, 2009), nöropsikolojik vakalar (Can ve Karakaş, 2005; Çakıcı vd., 2000; Çöp, Kültür ve Bakar, 2014), öğrenme güçlükleri (Durukan, Türkbay ve Cöngöloğlu, 2008; Asfuroğlu ve Fidan, 2016; Turgut, Erden ve Karakaş, 2010), ve mesleki eğitim (Kozhevnikov, Blazhenkova ve Becker, 2010; Olkun ve Altun, 2003; Turgut, 2007; Uttal ve Cohen, 2012; Wai, Lubinski ve Benbow, 2009) yer almaktadir.

ZD alan yazınında sıklıkla bulunan kadın-erkek farkının (Collins ve Kimura, 1997; Halpern ve Collaer, 2005; Hyde, 2014), öncelikle testi çözerken kullanılan stratejilerden kaynaklandığı düşünülmüştür (Kail vd., 1979). Performans farklarını, birçok araştırmacı bütüncül (holistic) ve analitik ya da parçalı (piecemeal) strateji kullanımına bağlamış (örn., Heil ve Jansen-Osmann, 2008; Lawton, 2010; Pezaris ve Casey, 1991; Just ve Carpenter, 1985; Yuille ve Steiger, 1982), daha iyi performans gösterenlerin bütüncül stratejiyi, zayıf performans gösterenlerin de parçalı stratejiyi kullananlar olduğunu belirtmişlerdir (Bethell-Fox ve Shepard, 1988). Janssen ve Geiser (2010) bütüncül stratejiyi bir zihinsel dönüștürme olarak tanımlar ve zihinsel döndürmenin hızlı bir şekilde tamamlandığını not eder. Bilâkis, analitik strateji uyaranın detaylarına odaklanır ve bu nedenle zihinsel döndürmeyi tamamlamak daha fazla zaman gerektirir. Erkeklerin kadınlardan daha fazla bütüncül strateji kullandıkları da bulgular arasındadır (Hegarty, 2018; Heil ve Jansen-Osmann 2008). Yani erkekler 3 boyutlu figürleri zihinlerinde bir bütün olarak döndürürken kadınların figürü önce parçalarına ayırarak her bir parçayı tek tek döndürdükleri, sonrasında parçaları birleştirerek sonuca vardıkları varsayılmıștır (Linn ve Petersen, 1985; Peters, 2005). Parçalı strateji, işlem sayısı itibariyle de fazla olduğu için daha yorucu bir çözüm olduğu gibi, daha uzun sürmekte ve cinsiyet ayrımının nedeni olarak ileri sürülmektedir.

Strateji kullanımının, görevin niteliğine ve zorluğuna bağlı olduğu da bulunmuştur (Glück ve Fitting, 2003; Kyllonen, Lohman ve Woltz, 1984). Hegarty'nin yeni çalışmasında, erkekler global şekil stratejisini kadınlar da şeklin lokal yönlerini daha çok analiz etmișlerdir (2018). Fonksiyonel manyetik rezonans görüntüleme (fMRI) araştırmaları da erkeklerin ve kadınların uzamsal problem çözmeyle meşgul olduklarında farklı stratejiler uyguladıklarını yordamıştır (Hugdahl, Thomsen ve Ersland, 2006; Jordan, Wustenberg, Heinze, Peters ve Jäncke, 2002). Katılımcılara ZD sırasında kullandıkları stratejileri soran özbildirim anketleri (Freedman ve Rovegno, 1981) ve yol bulmada farklılaşan strateji kullanım1 (Bosco, Longoni ve Vecchi, 2004; Dabbs vd., 1998; Lawton, 2010), erkeklerin ve kadınların sadece çoklu strateji uyguladığını değil, strateji tercihinde cinsiyetlerin farklılaştığını göstermektedir.

Mevcut araştırmada_ise, strateji kullanımını ortaya çıkarabilmek için özel bir modifikasyon yapılmış ve uyaranlar, hem bütüncül (örn., bütün) hem de parçalı (örn, kesik) stratejiyi tetikleyecek şekilde sunulmuştur. Kadınlardan oluşan bir örneklemde de bahsedilen strateji farkları bulunursa, bu strateji kullanımının cinsiyetten bağımsız olduğu desteklenecektir.

Bu çalışma, cinsiyeti sabit tutarak, uzamsal düşünce tarzının (örn., mekânın zihinsel temsili) ZD performansına etkisini araştırmaktadır. Daha önce, Tufts Üniversitesi ve Worcester Politeknik Enstitüsü (WPI)'nde yapılan çalışma (Bilge ve Taylor, 2017) tekrarlanmış, fakat prosedür salt kadınlardan oluşan ve Türkiye'den toplanan bir örneklemde uygulanmıştır. Daha önceki çalışma, karma bir örneklemle, farklı zihinsel temsile sahip olmanın (örn., kuşbakıșı temsil ve ișaret temsili) ZD performansını etkilediğini bulmuştur. Bu çalıșmayla amaçlanan; i) cinsiyet faktörünü sabit tutarak, zihinde oluşturulan uzamsal temsilin ZD performansinda bir fark yaratıp yaratmayacağını gözlemlemek ve ii) Türkiye'den toplanan bir örneklemle daha önceki çalışmayı tekrarlamak ve ZD performansına etki eden başka etmenlerin (uzamsal düşünce tarzı) de olabildiğini desteklemektir.

$\mathrm{Bu}$ araştırmayla, uzamsal bilginin büyük ve küçük ölçekteki işleyiş ve kullanımı arasında ilişki olup olmadığı irdelenmiștir. Büyük ölçekteki bilgi; mekânın zihinsel temsilini anketlerle ölmüş, küçük ölçekteki bilgi ise Zihinsel Döndürme (ZD) görevi ile ölçülmüştür. ZD görevinde değişik stratejilerin kullanılması, uzamsal bilgiyi işlemenin farkl1lıklarına da işaret eder. Bütüncül strateji kullanırken bilgi daha global bir seviyede işlenir, fakat parçalı strateji kullanırken bilginin işlenmesi daha lokal bir seviyede olur. Bunu irdelemek ve özellikle de parçalı stratejiyi aktive etmek için, bu deneyde yarıdan kesik şekiller kullanılmıştır. Bu prosedür, ZD problemlerinde kullanılan stratejiyi anlamak için geliştirilen yeni bir yaklaşımdır (Bilge ve Taylor, 2017; Boone ve Hegarty, 2017).

Bu çalışmayla, uzamsal düşünce tarzı ile ZD görevi ve bu testi çözerken kullanılan stratejiler arasındaki ilişki, cinsiyet gibi temel bir faktör kontrol edilerek irdelenmiștir. Bu bilgiler 1şı̆̆ı̆ında, çalışmanın hipotezleri: i) ZD testinde, iki figür arasındaki açı farkı arttıkça ka- 
1a

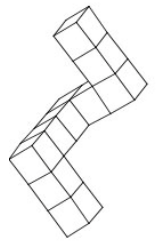

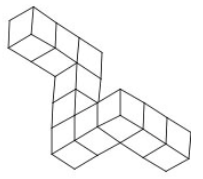

$1 \mathrm{~b}$

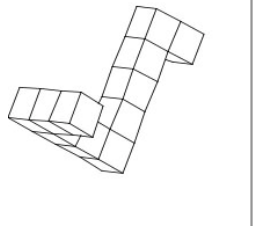

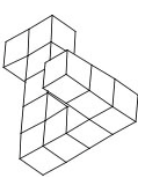

Şekil 1. Birbirinin aynı (Şekil 1a; sol) ve birbirinden farklı (Şekil 1b; sağ) şekilde sunulmuş uyaran çiftlerini göstermektedir.

tılımcıların performansında düşüş olacak; tepki zamanları yavaşlayıp doğruluk oranları azalacaktır, ii) zihinlerinde bir mekânı kuşbakışı temsil edenler ZD testinde daha hızlı ve doğru bir performans sergileyeceklerdir, iii) daha önceki bulgulara dayanarak (Bilge ve Taylor, 2017), açı farkı zihinsel temsille etkileşimde olacak; figürler arasındaki açı arttıkça, kuşbakışı ve işaret temsilleri arasındaki fark, kuşbakışı lehine, daha belirgin olacaktır, iv) zihinsel temsil ile figür şekilleri arasında etkileşim olması; iv.a) kuşbakışı temsil oluşturanların bütün figürlerde daha iyi bir performans ortaya koymaları ve daha ziyade bütüncül strateji kullanmaları, iv.b) mekân bilgisini işaretleyici noktalarla temsil edenlerin de kesik figürleri çevirirken zorlanmayacakları ve parçalı strateji kullanmaları da çalışmada ayrıca beklenmektedir.

\section{Yöntem}

\section{Örneklem}

Bu çalışmaya X Üniversitesi'nde okuyan 61 öğrenci katılmıştır. Katılımcıların hepsi kadın olup yaş ortalaması $21.2(\mathrm{~S}=2.6)$ yıldır. Uzamsal zihinsel temsiller incelendiğinde katılımcıların dağılımları şu şekildedir: kuşbakışı temsil $(\mathrm{N}=28, \% 45.9)$ ve işaret temsili $(\mathrm{N}=$ 33, \%54.1). Öğrenciler ders kredisi karşılığında ya da gönüllü olarak deneye katılım sağlamışlardır.

\section{Veri Toplama Araçları}

ZD uyaranlart, orijinal Shepard ve Metzler (1971) figürlerinin değiştirilmiş halleridir. Yine orijinal görevde yapıldığı gibi 3 boyutlu figür çiftlerini içerir. Uyaran çiftleri arasında açı farkı $\left(0^{\circ}, 30^{\circ}, 60^{\circ}, 90^{\circ}, 120^{\circ}, 150^{\circ}\right.$, $180^{\circ}$ ) ve uyaranların sunum şekli (bütün, kesik) manipüle edilmiştir (Şekil 1 ve Şekil 2). Her bir figür küplerden oluşur ve $\mathrm{x}, \mathrm{y}, \mathrm{z}$ eksenlerini kapsar. Üç boyutlu bu figürler, bütün șekillerden oluşur (bkz. Şekil 1). Kesik figürler, bütün figürlerin ikiye bölünmesiyle oluşturulmuştur (Şekil 2). Her figürün aynada yansımasını gös- teren versiyonları da oluşturulmuştur. Uyaran çiftleri, birbirinin (belli bir açıda döndürülmüş fakat yine de) aynısı (Şekil 1a) ya da birbirinden farklıdır (Şekil 1b) (aynada yansıma oldukları için örtüşmezler). Dikey bir çizgi, uyaran çiftini ayırır. Bütün ve kesik figürler blok dizayn kullanılarak gösterilmiş; bir katılımcı önce bütün figürleri, sonra tüm kesik figürleri görmüş ve bloklar eş ağırlıkla sunulmuştur. Toplamda 126 adet figür çiftinden oluşan soru kullanılmış, bunların yarısı bütün (63) yarısı da kesik (63) gösterilmiştir. Ayrıca, denemelerin yarısı aynı (63) yarısı da farklı (63) çiftlerden oluşmuştur.

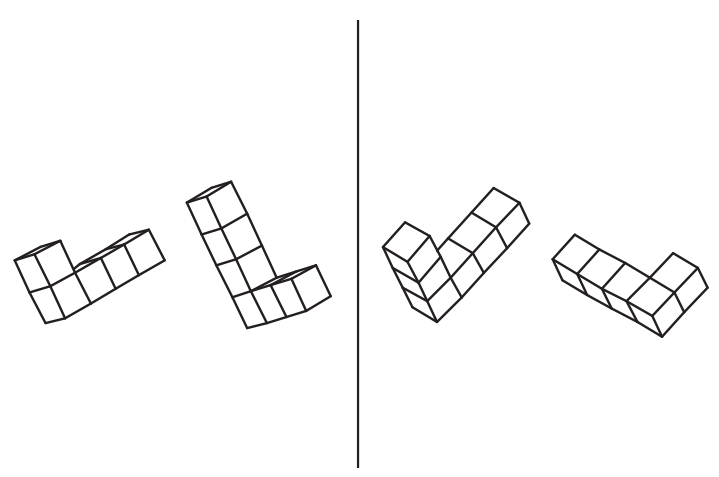

Şekil 2. Kesik şekilde sunulmuş bir uyaran çiftine örnektir.

Anketler yoluyla uzamsal ve mekânsal bilgi işleyişine dair bilgi toplanmıştır. Bunlar, kişinin uzamsal temsil ve yön bulma duygularını ölçen iki adet özbildirim ölçeğidir; Uzamsal Temsil Anketi ve Santa Barbara Yön Duyusu Ölçeği.

Uzamsal Temsil Anketi (Pazzaglia ve De Beni, 2001), katılımcıları uzamsal düşünüş tarzlarına göre kategorize etmeye yarayan bir ölçektir. Toplamda 17 soru bulunur ve "Şehrinizde veya memleketinizdeyken, doğal bir şekilde ana yönleri ayırt ediyor musunuz? Şöyle 
Tablo 1. Katılımcıların Uzamsal Temsillere ve Yön Duyusu Puanlarına göre Dağılımı

\begin{tabular}{|c|c|c|c|c|}
\hline & & \multicolumn{3}{|c|}{ Yön Duyusu Puanı } \\
\hline & & Yüksek & Düşük & TOPLAM \\
\hline Uzamsal & İşaret & $\begin{array}{c}15 \\
(45.5 \%)\end{array}$ & $\begin{array}{c}18 \\
(54.5 \%)\end{array}$ & 33 \\
\hline Temsil & Kuşbakışı & $\begin{array}{c}17 \\
(60.7 \%)\end{array}$ & $\begin{array}{c}11 \\
(39.3 \%)\end{array}$ & 28 \\
\hline TOPLAM & & 32 & 29 & 61 \\
\hline
\end{tabular}

ki, Kuzey, Güney, Doğu ve Batı'nın nerede olduğunu biliyor musunuz?" gibi sorular içerir. Her bir soru ya da ifade 5'li Likert tipi bir ölçek üzerinde $(1=$ Kesinlikle katılmıyorum, 5 = Kesinlikle katılıyorum) belirtilmiştir. Ölçeği geliștiren araştırmacıların kodlaması takip edilmiş (Pazzaglia ve De Beni, 2001; 2006) ve sonucunda, mekâna dair düşünürken, kişinin zihninde yatkınlıkla işaret temsili mi kuşbakışı temsil mi oluşturduğuna karar verilmiştir. Ölçeğin iç geçerliliği 0.75 olarak bulunmuştur (Pazzaglia ve De Beni, 2001).

Yön Duyusu Ölçeği (Hegarty, Richardson, Montello, Lovelace ve Subbiah, 2002), uzamsal mekânsal beceriyi değerlendirmek için oluşturulmuş bir ölçektir. Kat1lımcının yaşı ve cinsiyeti üzerine demografik soruları, 15 olumlu - 15 olumsuz açıklama takip eder. Ífadelerden bazıları "Yön tarif etmede çok iyiyimdir" ya da "Yeni bir şehirde çok kolay kaybolurum"dur. Ölçeğin puanlamas1 7'li Likert tipi, "1" (kesinlikle katıllyorum) ile "7" (kesinlike katılmıyorum) arasında derecelendirilmiştir. Araştırmacıların puanlama sistemi takip edilerek her bir katılımcının toplam skoru belirlenmiş, yüksek skor yüksek yön duyusuna işaret etmiştir. Ölçeğin iç geçerlilik değeri .88 dir (Hegarty ve ark., 2002).

\section{İşlem}

Katılımcılar, ... Üniversitesi ... Laboratuvarı'nda test edilmişlerdir. Her bir deney odasına tek başlarına alınmış, kontrol veya deney grubuna seçkisiz şekilde atanmışlardır. Onam Formu'nu imzalayan katılımcılar bilgisayar ortamında ZD görevini tamamlamışlardır. Bütün, kesik uyaran blokları arasında küçük bir ara verilmiş, her bir bloğa 7 adet geri dönüşlü deneme yapılarak başlanılmıştır. Katılımcılar, görevi 30-45 dk. aralığında tamamlamış, kalem-kağıtla işaretledikleri 2 anketi doldurarak deneyi bitirmişlerdir. Bu araştırma, ... Üniversitesi Etik Kurulu'ndan onay almıştır.

\section{Bulgular}

Araştırmada, bağımsız değişkenler; Açı Fark1 (0$180^{\circ}$ ), Uyaran Şekli (bütün ve kesik) Uzamsal Temsil (kuşbakıșı ve işaret) ve Yön Duyusu (yüksek ve düşük) iken bağımlı değişkenler; tepki zamanı (TZ) ve doğruluk oranıdır. Açı Farkı ve Uyaran Şekli denek-içi değişken, Uzamsal Temsil ve Yön Duyusu ise denekler-arası değişkenlerdir. Veriler temizlenirken, katılımcıların ZD sorularına verdikleri cevaplar ve TZ eşleștirildi. Her bir katılımcının, açı tepkileri baz alınarak 2 standart sapma (SS) alt ve üstündeki TZ verileri elendi. Toplam veri setinin \%3.15'i aykırı değerlere sahip olduğu için elendi. Ayrıca, ortalama doğruluk oran $1 \% 50$ 'nin altında kalan 8 kișinin verisi de analizlere dahil edilmedi.

Uzamsal Temsil ve Yön Duyusu, Uzamsal Düşünce Tarzını açıklamak için kullanılan iki değişkendir. Bu iki değişken arasındaki ilişki ki-kare analiziyle incelendi. Uzamsal Temsil ve Yön Duyusu arasında anlamlı bir ilişki bulunmad1, $X^{2}(1, \mathrm{~N}=61)=1.41, p=.23$. Kontrol amacıyla yapılan bu analiz sonucu, işaret temsili ile düşük yön duyusu, kuşbakışı temsil ile yüksek yön duyusu birebir örtüşmemiştir. Daha önceki bulgulara da dayanarak (Bilge ve Taylor, 2017) uzamsal düşünce tarzını belirleyebilmek için Uzamsal Temsil ölçeği kriter alınmıştır. Yine de Tablo 1'de bu iki değişkenin skorlarına göre katılımcıların dağılımı sunulmuştur.

Veriler karışık desen ANOVA kullanılarak analiz edildi. Öncelikle, 2 (Uyaran Şekli) X 7 (Açı Farkı) X 2 (Uzamsal Temsil) ANOVA kullanıldı, çünkü Uzamsal Temsil kategorilerinin kişinin uzamsal düşünce yatkınlığını ayrıștırmada belirleyici olduğu önceki çalışmalarda bulunmuştur (Bilge ve Taylor, 2017; Pazzaglia ve De Beni, 2006). Yön Duyusu değişkeninin Uyaran Şekli ve Açı Farkına etkisi de ayrı bir analizle değerlen-

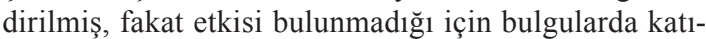



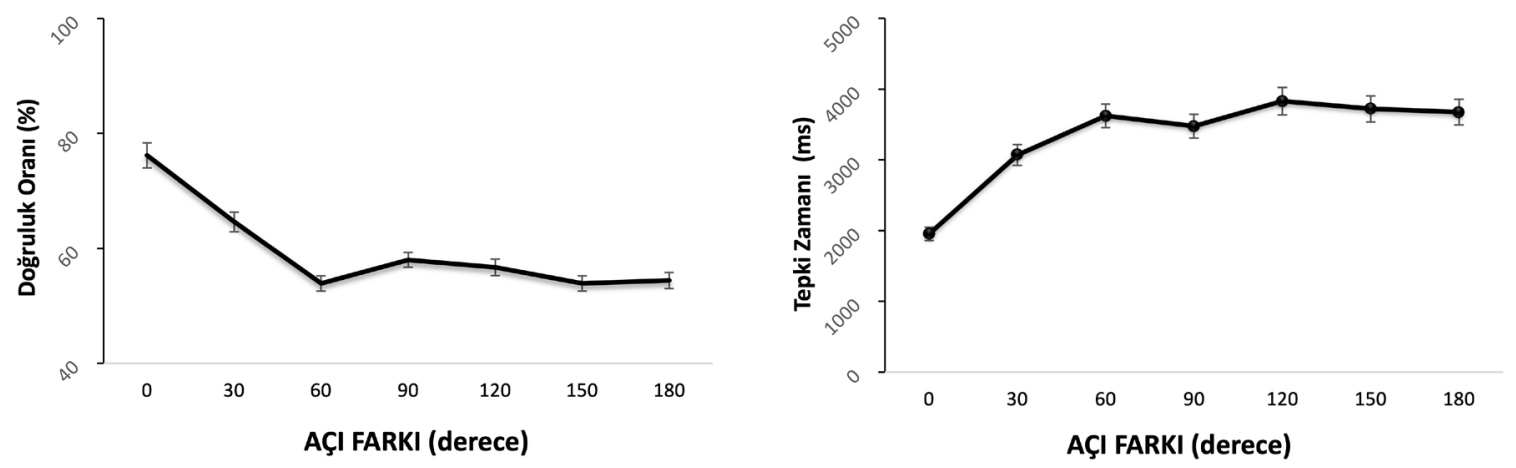

Şekil 3. Katılımcıların Zihinsel Döndürme (ZD) görevinde ortalama doğruluk oranları (Şekil 3a; sol) ve tepki zamanları (Şekil 3b; sağ) sunulmuştur. Șekildeki dikey hata çubukları, standart hatayı göstermektedir.

lımcılar arası değişken olarak sadece Uzamsal Temsil sunulmuştur.

Mauchly'nin testi tepki zamanı için Açı Fark1, $X^{2}(20)=140, p<.001$, ve doğruluk oranı için $X^{2}(20)$ $=78.5, p<.001$ küresellik varsayımını ihlâl etti. $\mathrm{Bu}$ yüzden serbestlik derecesi $(S)$, tepki zamanı $(\varepsilon=.43)$ ve doğruluk $(\varepsilon=.61)$ için Greenhouse-Geisser küresellik tahminine uygun olarak düzeltildi. Mauchly'nin testi, Açı Farkı X Uyaran Şekli etkileşiminde; tepki zamanı $X^{2}(20)=33.8, p=.028$ ve doğruluk $X^{2}(20)=37.1, p=$ .02 için küreselik varsayımının ihlâl edildiğini gösterdi. Tepki zamanı $(\varepsilon=.81)$ ve doğruluk için $(\varepsilon=.92)$ serbestlik derecesi (df) Huynh-Feldt tahminleri kullanılarak düzeltildi.

Katılımciların ortalama tepki zamanı 3335 ms. ve ortalama doğruluk oranı \%59.7 dir. Açı Farkı, hem tepki zaman1, $F(2.59,152.59)=82.8, p<.001, \eta \mathrm{P} 2=$ .584 , (Şekil 3a), hem de doğruluk oranı $F(3.66,215.78)$
$=33.07, p<.001, \eta \mathrm{P} 2=.359$ (Şekil 3b) verileri için anlamlı bulunmuştur. Açı Farkına uygulanan polinom kontrast analizi, artan tepki zamaniyla $(F(1,59)=107.3$, $p<.001, \eta \mathrm{P} 2=.645)$ ve azalan doğruluk oranıyla $(F(1$, $59)=50.7, p<.001, \eta \mathrm{P} 2=.462)$ klasik Aç1 Fark1 eğrisini göstermiştir.

Uzamsal Temsilin temel etkisi bulunmazken tepki zamanı için Açı Farkı X Uzamsal Temsil etkileşimi bulunmuştur, $F(6,354)=3.53, p=.002, \eta \mathrm{P} 2=.057$. Zihinlerinde işaret temsili ya da kuşbakışı temsil oluşturan katılımcılar, uyaran çifti arasındaki fark az olduğunda benzer performans sergilemiş, fakat birbirlerine uydurmak için figürleri zihinlerinde daha çok döndürmeleri gerektiğinde $\left(120^{\circ}-180^{\circ}\right)$ işaret temsiline yatkın bireylerle kuşbakışı temsile yatkın bireyler arasında fark anlamlı olarak artmıștır. Kușbakıșı temsil olușturan katılımcılar, diğer gruba oranla görevi daha hızlı yapmışlardır (bkz. Şekil 4).

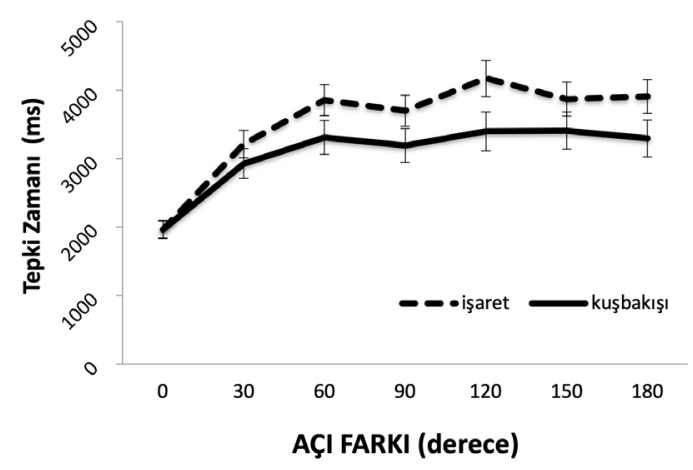

Şekil 4. Kuşbakışı ve işaret temsil (Uzamsal Temsil) kullanan katılımcıların, uyaran çiftleri arasındaki açı farkı arttıkça Zihinsel Döndürme(ZD)'de değişen ortalama tepki zamanlarını göstermektedir. Şekildeki dikey hata çubukları, standart hatayı göstermektedir. 

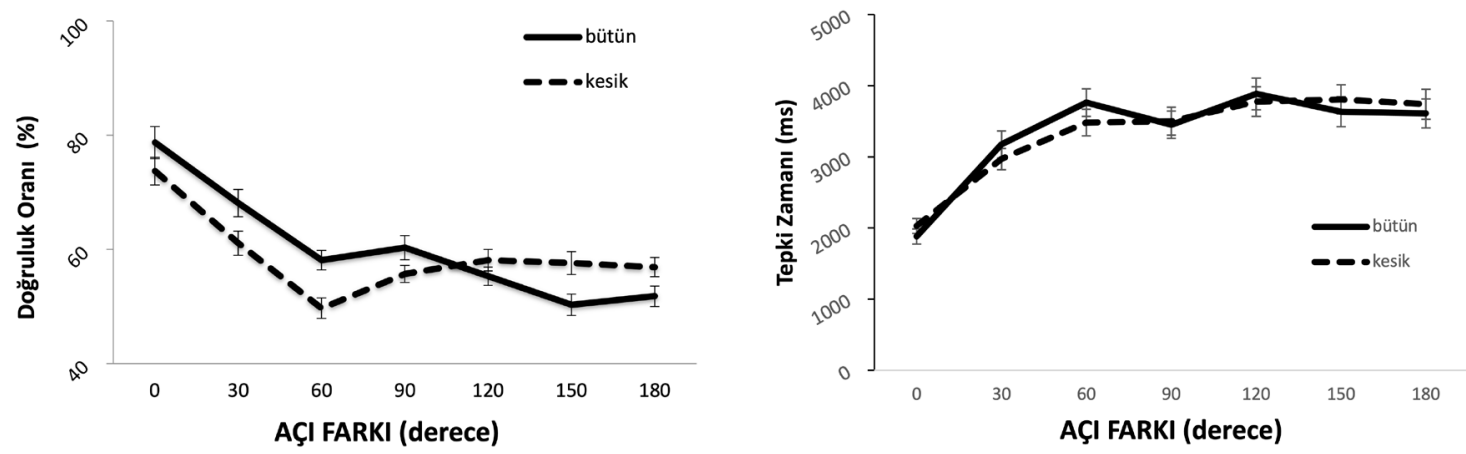

Şekil 5. Zihinsel Döndürme (ZD) performansında katılımcıların zihinlerinde döndürdükleri uyaran şekillerine (bütün, kesik) bağlı olarak, açı farkına göre değişen ortalama tepki zamanı (Şekil 5a; sol) ve doğruluk oranı (Şekil 5b; sağ) görülmektedir. Şekildeki dikey hata çubukları, standart hatayı göstermektedir.

Uyaran Şeklinin temel etkisi bulunmamıș, fakat hem TZ $(F(5.45,321.55)=2.59, p=.022, \eta \mathrm{P} 2=.042)$ hem de doğruluk oranı için $(F(5.54,326.86)=6.43, p<$ .001, ๆP2 = .098) Aç1 Fark1 X Uyaran Şekli etkileşimi bulunmuştur. Bütün figürler ve kesik figürlerin zihinde döndürülmesi uyaranlar arasındaki açıya bağlı değişiklik göstermiş, uyaranlar arasında açı farkı görece az iken kesik figürler daha doğru bir şekilde döndürülmüştür. Bununla beraber, belli bir açı farkından $\left(\sim 110-115^{\circ}\right)$ sonra kesik ve bütün figürlerin döndürülme kalıpları yer değiştirerek açı farkı artınca bütün figürler daha doğru cevaplanmıştır (Şekil 5).

\section{Tartışma}

$\mathrm{Bu}$ çalışmayla ZD alan yazınında sıklıkla değinilen bireysel performans farklarının (Collins ve Kimura, 1997; Linn ve Petersen, 1985; Voyer vd., 1995; Voyer vd., 2017) nedeni irdelenmiş, uzamsal düşüncenin zihinsel döndürme (ZD) performasına etki ettiği bulunmuştur. Araştırma sonuçlarının, cinsiyet faktörü kontrol edilerek salt kadınlardan oluşan bir örneklemde gözlendiği dikkate alınınca, uzamsal ve mekânsal testlerde çıkan farkları açıklarken cinsiyetin tek faktör olmayabileceği, bireyin zihninde oluşturduğu uzamsal temsillerin de uzamsal beceriyi etkileyebileceği gösterilmiştir.

İlk olarak, ZD alan yazınının ana bulgusu olan Açı Farkı (Shepard ve Metzler, 1971) etkisi bu çalışmayla bulunmuş; uyaran çiftleri arasındaki açı fark1 arttıkça katılımcıların üç boyutlu figürleri zihinlerinde daha yavaş ve daha yanlış döndürdükleri bulunmuştur. Alan yazında, uyaran özellikleri veya katılımcıdan istenen görevin ZD performansını etkilediği bulunmuştur. Uyaranın zorluğu (örn., Bethell-Fox ve Shepard, 1988; Doyle ve Voyer, 2013; Doyle, Voyer ve Lesmana, 2015; Folk ve Luce, 1987), 3 boyutlu veya 2 boyutlu olmas1 (örn., Bauer ve Jolicoeur, 1996; Hampson, Levy-Cooperman ve Korman, 2014) ya da katılımcılara verilen yönergeler (örn., Sharps, Price ve Williams, 1994) ZD performansında farklılıklara yol açmıştır. Örneğin, zihinde döndürülecek açı arttıkça, katılımcılar soruları daha yavaş ve daha yanlıș çözmeye başlamışlar, bu da açı farkıyla beraber görevin zorlaştığını göstermiştir (Bilge ve Taylor, 2017). Bu çalışmayla, önceki bulgular yinelenmiş, uzamsal düşünce konusunda farklılaşan bireylerin ZD görevinin zorluğuna göre performanslarının farklılaşt1ğını bulmuştur. Katılımcıların, bir mekânı zihinlerinde canlandırırken kuşbakışı veya işaret temsili oluşturmaları, ZD testindeki figürlere de yansımış, figürler arasındaki açı arttıkça uzamsal temsil arasındaki fark kuşbakışı lehine belirgin hale gelmiştir.

Araştırmada uzamsal yeteneği ölçmek için ZD kullanılmıştır fakat uzamsal biliş çok boyutludur ve sadece küçük ölçekte irdelenebilecek bir alan değildir. Büyük ölçekteki uzamsal ve mekânsal bilginin nasıl değerlendirildiği de önemlidir. Mekânsal bilgiyi işleme konusunda da (örn; navigasyon, yol bulma, yol tarifi) cinsiyet farklilıkları alan yazında yerini almıştır (Bosco vd., 2004; Coluccia ve Louse, 2004; Dabbs vd., 1998; Driscoll vd., 2005; Golledge vd., 1993; Lawton, 2010). ZD performansı ile büyük ölçekte görülen farklılıklar arasındaki olası ilişkiyi irdelemek, cinsiyet faktörünün de daha yakından incelenmesini sağlayabilir. Olduğumuz yeri, gideceğimiz hedefi, yeni öğrendiğimiz ya da hatırlad1ğımız mekânları düşünürken uzamsal bilgiyi düşünür ve işleriz. Uzamsal düşünce tarzı, bu testlerdeki performanS1 etkileyen önemli bir faktördür (Bilge ve Taylor, 2017; Pazzaglia ve De Beni, 2006). Önceki çalışmalarda kadın-erkek karma bir örneklemde bulunan sonuçlar (Bilge ve Taylor, 2017), bu araştırmada salt kadın örneklemde 
bulunmuştur. Başka bir deyişle, bir alanı zihinlerinde global, alosentrik ve kuşbakışı temsil etmeye yatkın olan kişiler, lokal-egosentrik işleyen ve işaret temsiline yatkın olan kişilerden farklı bir performans sergilemişlerdir. Özellikle, ZD görevi zorlaştıkça, kuşbakışı temsil yapanların işaret temsilinden daha hızlı olduğu bulunmuştur. $\mathrm{Bu}$ da uzamsal düşünce tarzının, uzamsal yetenek performansıyla ilişkisini gösterir.

$\mathrm{Bu}$ araştırmada, kadın-erkek farklarının nedeni olarak önerilen farklı strateji (Bethell-Fox ve Shepard, 1988; Heil ve Jansen-Osmann, 2008; Janssen ve Geisser, 2010; Kail vd., 1979) kullanımını tetikleyebilecek uyaran şekilleri kullanılmıştır (Bilge ve Taylor, 2017; Boone ve Hegarty, 2017). Bütüncül strateji kullananların, bütün figürleri döndürürken avantajlı olacakları çünkü kullanageldikleri stratejinin uyaranla uyumlu olması olduğu varsayılmıştır. Bütün figürlerin yanı sıra kesik figürlerin kullanılması ise, ZD sorularını çözerken farklı strateji kullanabilecek (örn., parçalı) gruplara daha uyumlu bir uyaran sunabilmektir. Kadınlardan oluşan bir grup içinde de strateji-nedenli farklılıklar ortaya çıkarsa bunun, alan yazında önerildiği gibi "bütüncül stratejiyi erkekler kullanır, parçalı stratejiyi kadınlar kullanır” gibi bir çıkarımla açıklanmasının yetersiz olacağı öngörülmüştür. Çalışmanın sonucunda, ZD problemlerinin bütün ya da kesik şekilli figürlerden oluşması kendi bașına performansı etkilememiş fakat figürler arasındaki açı arttıkça uyaran şekillerine verilen tepki değişmiştir. Daha önceki çalışmayı (Bilge ve Taylor, 2017) da destekleyen bu bulgu, uyaran şekillerine uygulanabilecek olası strateji farklarının ancak problem zorlaștıkça yani açı farkı arttıkça ortaya çıkmasıyla açıklanabilir. Açı farkı az olunca katılımcıların kesik şekilleri daha doğru döndürdüklerini, büyük açı farklarında ise bütün şekillerin kesiklerden daha doğru bir şekilde cevaplandığını göstermiştir. Bu sonuçlar, yine artan açı farkıyla ZD görevinin zorlaşması ile açıklanabilir (Heil ve Jansen-Osmann, 2008). Görev görece kolayken (açı farkı az iken) parçalı stratejiyle uyumlu kesik figürleri daha doğru döndürmüşler fakat görev zorlaştıkça bütüncül-strateji uyumlu figürleri bir bütün olarak döndürünce daha doğru yapmışlardır. $\mathrm{Bu}$ davranış kalıbı da alan yazınla uyumludur (Hampson, Levy-Cooperman ve Korman, 2014).

Mevcut araştırma, Bilge ve Taylor (2017)'ın yöntemini takip ederek aynı uyaranları kullanmıştır. Fakat, gerek ortalama döndürme hızı (3335 ms) gerek de doğruluk oranı $(59.7 \%)$, önceki araştırmaya nazaran düşüktür (6240 ms; 77.9\%). İki çalışma karşılaştırıldığında, mevcut araştırmanın doğruluk oranındaki düşüş ve tepki zamanındaki hızlanma olası bir hız-doğruluk takasına işaret etmektedir. Daha önceki araştırmanın öğrenci profili ile bu araştırmanın öğrenci profili, araștırma kültürüne aşina olma, psikoloji deneylerinin katılıp katılmama gibi değişkenler de görünürdeki performans farkının nedenlerinden olabilir. Ayrıca, bu araştırmada salt kadın örneklem kullanıldığı gözardı edilmemelidir. Zihinsel döndürme işleminin farklı aşamalarında etkili olabilecek kadın-erkek farkları ile hız-doğrıuluk takas oranı arasındaki ilişki ileriki çalışmalarda irdelenebilir.

$\mathrm{Bu}$ araştırmada, psikoloji öğrencilerinden oluşan salt kadın bir örneklem grubu kullanılmıştır. Temsili örneklemin daha geniş tutulması bulguların genellenebilmesi açısından önemlidir. İlerideki araştırmalar için başka bölümlerde eğitim gören öğrenciler, daha geniş bir yaş grubu ile örneklem sayısı fazlalaştırılabilir. Alan yazındaki araştırmalar, bilim-teknoloji-mühendislik-matematik (Science-Technology-Engineering-Math; STEM) alanlarına yatkınlığı olan kişilerin uzamsal becerilerinin de daha iyi olduğunu (Uttal ve Cohen, 2012) ve bu alanlarda ileride daha başarılı olduklarını (Kozhevnikov, Motes ve Hegarty, 2007; Vasilyeva ve Lourenco, 2012) bulmuşlardır. Kısacası, farklı bölümlerden öğrencileri araştırmaya katmak uzamsal düşünceyi daha iyi irdelemeyi sağlayacaktır.

Araştırma bulgularına göre, geliştirilmesi gereken noktalardan bir diğeri de katılımcıların uzamsal düşünce tarzlarının belirlenmesidir. Uzamsal düşünce, alan yazına bağlı olarak öz-bildirimle belirlenmiş (Pazzaglia ve De Beni, 2001; 2006) ve katılımcılar, işaret veya kuşbakışı temsil yapmaya yatkın olarak kategorize edilmişlerdir. Büyük ölçekte mekânsal bilgi işleyişi bir başka öz-bildirim ölçeğiyle daha ölçülmüş (Hegarty vd., 2002) fakat iki ölçek arasında tam örtüşme bulunmamıştır. İleriki çalışmalarda, öz-bildirimleri teyit edecek şekilde daha objektif ölçümler yapılmalı ve kişilerin büyük-ölçekte mekânsal bilişlerini yordayabilecek görevler geliştirilerek, veriler öz-bildirimlerle beraber toplanmalıdır.

ZD problemlerini çözmek için kullanılan mekanizmaları incelemek, alan yazındaki cinsiyet farkını anlamanın en önemli aşaması olarak düşünülebilir. Ancak aynı cinsiyet grubunun performansında da önceki bulgularla örtüşen değişimler gözlemlendi. Dolayısıyla ZD performans farkının sadece cinsiyet ile açıklanabilecek bir problem olmadığı, ZD performanslarında diğer faktörlerin de önemli rol oynadığı ve durumun alternatif açıklamalar gerektiren bir problem olduğu sonucu ortaya çıkmaktadır. Kadınlardan oluşan bir örneklemde farklılaşan sonuçlar gözlenmesi, alan yazında cinsiyet farkıyla açıklanan performans farkının, uzamsal bilgiyi işleyiş tarzı gibi açıklayıcı başka faktörleri de olabileceğine işaret eder.

Günlük hayatta sıkça başvurduğumuz uzamsal ve mekânsal bilgiyi gerek küçük-ölçekte gerekse büyük-ölçekte işliyoruz. Çevremizdeki nesnelerin ne olduğunu ve konumunu anlamaktan, bulunduğumuz yerde yönümüzü belirlemeye ve harita ya da GPS sistemleri gibi araçları 
kullanarak yolumuzu bulmaya kadar tüm bu süreçlerde uzamsal bilginin kodlanması, temsili ve kullanılması vardır. Özetle, bir uzamın ya da mekânın nasıl algılandığ1 ve zihinde tutulduğunu araştırmak, günlük aktivitelerimizi kolaylaştırıcı ve öngörücü bilgiler sağlayacaktır.

\section{Kaynaklar}

Alkan, F. ve Erdem, E. (2011). A study on developing candidate teachers' spatial visualization and graphing abilities. Procedia-Social and Behavioral Sciences, 15, 3446-3450.

Arpac1, B. (2009). Posterior (Bilateral Parietooksipital) Kortikal Atrofi: Bir Olgu Sunumu. Archives of Neuropsychiatry/Nöropsikiatri Arşivi, 46, 4.

Asfuroğlu, B. Ö. ve Fidan, S. T. (2016). Özgül Öğrenme Güçlüğü/Specific Learning Disorders. Osmangazi Journal Of Medicine, 38.

Bauer, B. ve Jolicoeur, P. (1996). Stimulus dimensionality effects in mental rotation. Journal of Experimental Psychology: Human Perception and Performance, 22, 82-94.

Bethell-Fox, C. E. ve Shepard, R. N. (1988). Mental Rotation: Effects of stimulus complexity and familiarity. Journal of Experimental Psychology: Human Perception and Performance, 14, 12-23.

Bilge, A. R. ve Taylor, H. A. (2017). Framing the figure: Mental rotation revisited in light of cognitive strategies. Memory \& Cognition, 45(1), 63-80.

Boone, A. P. ve Hegarty, M. (2017). Sex differences in mental rotation tasks: Not just in the mental rotation process!. Journal of Experimental Psychology: Learning, Memory, and Cognition, 43(7), 1005.

Bosco, A., Longoni, A. M. ve Vecchi, T. (2004). Gender effects in spatial orientation: Cognitive profiles and mental strategies. Applied Cognitive Psychology: The Official Journal of the Society for Applied Research in Memory and Cognition, 18(5), 519-532.

Butler, T., Imperato-McGinley, J., Pan, H., Voyer, D., Cordero, J., Zhu, Y-S., Stern, vd. (2006). Sex differences in mental rotation: Top-down versus bottom-up processing. NeuroImage, 32, 445-456.

Can, H. ve S. Karakaş. (2005). Alzheimer Tipi Demans ve Birinci Basamakta Nöropsikolojik Değerlendirme. Sürekli Tıp Eğitimi Dergisi ,14(3), 22-25.

Carroll, J. B. (1993). Human cognitive abilities: A survey of factor-analytic studies. Cambridge University Press.

Choi, J. Y., Hild, S., Zeiher, J., Schauß, P., Rubio-Abadal, A., Yefsah, T. ve Gross, C. (2016). Exploring the many-body localization transition in two dimensions. Science, 352(6293), 1547-1552.

Collins, D. W. ve Kimura, D. (1997). A large sex difference on a two-dimensional mental rotation task. Behavioral Neuroscience, 111, 845-849.

Coluccia, E. ve Louse, G. (2004). Gender differences in spatial orientation: A review. Journal of Environmental Psychology, 24(3), 329-340. 
Cooper, L.A. ve Shepard, R.N. (1973). Chronometric studies of the rotation of mental images. In: Chase, W.G. (Ed.), Visual Information Processing. New York: Academic Press.

Çakıc1, M., Çıtak, S., Çakııı, E., Küçükali, İ., Yandim, D., Erkoç, S. ve Arkonaç, O. (2000). Sağlıklı Bireylerde Nöropsikolojik Değerlendirme Sonuçlarının Nörolojik İşaretlerle Bağıntısının Araştırılması. Düşünen Adam Dergisi.

Çöp, E., Kültür, S. ve Bakar, E. E. (2014). Metalik Civa Zehirlenmesi ve Nöropsikolojik Etkileri: Bir Olgu Sunumu. Türk Psikiyatri Dergisi, 25,1.

Dabbs Jr, J. M., Chang, E. L., Strong, R. A. ve Milun, R. (1998). Spatial ability, navigation strategy, and geographic knowledge among men and women. Evolution and Human Behavior, 19(2), 89-98.

Doyle, R. A. ve Voyer, D. (2013). Bodies and occlusion: Item types, cognitive processes, and gender differences in mental rotation. The Quarterly Journal of Experimental Psychology, 66, 801-815.

Doyle, R. A., Voyer, D. ve Lesmana, M. (2015). Item type, occlusion, and gender differences in mental rotation. The Quarterly Journal of Experimental Psychology, 1-15.

Driscoll, I., Hamilton, D. A., Yeo, R. A., Brooks, W. M. ve Sutherland, R. J. (2005). Virtual navigation in humans: the impact of age, sex, and hormones on place learning. Hormones and Behavior, 47(3), 326-335.

Durukan, İ., Türkbay, T. ve Cöngöloğlu, A. (2008). “The Effects of Methylphenidate on Various Components of Visual Attention in Children with Attention-Deficit Hyperactivity Disorder", Turkish Journal of Psychiatry 19, 4.

Eals, M. ve Silverman, I. (1994). The hunter-gatherer theory of spatial sex differences: Proximate factors mediating the female advantage in recall of object arrays. Evolution and Human Behavior, 15(2), 95105.

Easton, R. D. ve Sholl, M. J. (1995). Object-array structure, frames of reference, and retrieval of spatial knowledge. Journal of Experimental Psychology: Learning, Memory, and Cognition, 21(2), 483.

Ekstrom, R., French, J., Harman, H. ve Dermen, D. (1976). Kit of factor-referenced cognitive tests. Princeton, NJ: Educational Testing Services.

Folk, M. D. ve Luce, R. D. (1987). Effects of stimulus complexity on mental rotation rate of polygons. Journal of Experimental Psychology: Human Perception and Performance, 13, 395-404.

Freedman, R. J. ve Rovegno, L. (1981). Ocular dominance, cognitive strategy, and sex differences in spatial ability. Perceptual and Motor Skills, 52, 651-654.
Gardony, A. L., Taylor, H. A. ve Brunye, T. T. (2014). What does physical rotation reveal about mental rotation? Psychological Science, 25, 605-612.

Glück, J. ve Fitting, S. (2003). Spatial strategy selection: Interesting incremental information. International Journal of Testing, 3(3), 293-308.

Golledge, R. G., Ruggles, A. J., Pellegrino, J. W. ve Gale, N. D. (1993). Integrating route knowledge in an unfamiliar neighborhood: Along and across route experiments. Journal of Environmental Psychology, 13(4), 293-307.

Hahn, N., Jansen, P. ve Heil, M. (2010). Preschoolers' mental rotation: Sex differences in hemispheric asymmetry. Journal of Cognitive Neuroscience, 22(6), 1244-1250.

Halpern D.F. ve Collaer M. (2005). Sex differences in visuospatial abilities: More than meets the eye. In Shah P., Miyake A. (Eds.), Higher-level visuospatial thinking and cognition. Cambridge, MA: Cambridge University Press.

Hampson, E., Levy-Cooperman, N. A. ve Korman, J. M. (2014). Estradiol and mental rotation: relation to dimensionality, difficulty, or angular disparity? Hormones and Behavior, 65, 238-248.

Hausmann, M., Slabbekoorn, D., Van Goozen, S. H., Cohen-Kettenis, P. T. ve Güntürkün, O. (2000). Sex hormones affect spatial abilities during the menstrual cycle. Behavioral Neuroscience, 114(6), 1245.

Hegarty, S. (2018). Home-school relations: A perspective from special education. In Parents and Schools (1993) (pp. 117-130). Routledge.

Hegarty, M., Richardson, A. E., Montello, D. R., Lovelace, K. ve Subbiah, I. (2002). Development of a self-report measure of environmental spatial ability. Intelligence, 30, 425-447.

Hegarty, M. ve Waller, D. (2004). A dissociation between mental rotation and perspective-taking spatial abilities. Intelligence, 32(2), 175-191.

Heil, M. ve Jansen-Osmann, P. (2008). Sex differences in mental rotation with polygons of different complexity: Do men utilize holistic processes whereas women prefer piecemeal ones?. The Quarterly Journal of Experimental Psychology, 61, 683-689.

Hugdahl, K., Thomsen, T. ve Ersland, L. (2006). Sex differences in visuo-spatial processing: An fMRI study of mental rotation. Neuropsychologia, 44, 1575-1583.

Hyde, J. S. (2014). Gender similarities and differences. Annual Review of Psychology, 65, 373-398.

Janssen, A. B. ve Geiser, C. (2010). On the relationship between solution strategies in two mental rotation tasks. Learning and Individual Differences, 20(5), 473-478. 
Jordan, K., Schadow, J., Wuestenberg, T., Heinze, H-J., Peters, M. ve Jancke, L. (2002). Women and men exhibit different cortical activation patterns during mental rotation tasks. Neuropsychologia, 40, 2397-2408.

Just, M. A. ve Carpenter, P. A. (1976). Eye fixations and cognitive processes. Cognitive Psychology, 8, 441-480.

Kadam, K. ve Iyer, S. (2014, July). Improvement of Problem Solving Skills in Engineering Drawing Using Blender Based Mental Rotation Training. 2014 IEEE 14th International Conference on Advanced Learning Technologies (pp. 401-402). IEEE.

Kail, R., Carter, P. ve Pellegrino, J. (1979). The locus of sex differences in spatial ability. Perception \& Psychophysics, 26, 182-186.

Kandemir, M., Örnek, İ. ve Kırbaş, D. (2009). İnfratentöriyal İnmelerde Kognitif Etkilenme. Turkish Journal of Neurology/Turk Nöroloji Dergisi,15, 4.

Kozhevnikov, M., Blazhenkova, O. ve Becker, M. (2010). Trade-off in object versus spatial visualization abilities: Restriction in the development of visual-processing resources. Psychonomic Bulletin \& Review, 17(1), 29-35.

Kozhevnikov, M., Motes, M. A. ve Hegarty, M. (2007). Spatial visualization in physics problem solving. Cognitive Science, 31, 549-579.

Kurt, M., Bekci, B. ve Karakas, S. (2004). The effect of estrogene replacement therapy on cognitive processes. International Journal of Psychophysiology, 54, 1-2.

Kyllonen, P. C., Lohman, D. F. ve Woltz, D. J. (1984). Componential modeling of alternative strategies for performing spatial tasks. Journal of Educational Psychology, 76(6), 1325.

Lawton, C. A. (2010). Gender, spatial abilities, and wayfinding. In Handbook of gender research in psychology (pp. 317-341). Springer New York.

Likert, R. ve Quasha, W. H. (1969). Revised Minnesota paper form board test. Psychological Corporation.

Linn, M. C. ve Petersen, A. C. (1985). Emergence and characterization of sex differences in spatial ability: A meta-analysis. Child Development, 56, 1479-1498.

Lippa, R. A., Collaer, M. L., \& Peters, M. (2010). Sex differences in mental rotation and line angle judgments are positively associated with gender equality and economic development across 53 nations. Archives of Sexual behavior, 39(4), 990-997.

Lohman, D. F. (1986). The effect of speed-accuracy tradeoff on sex differences in mental rotation. Perception \& Psychophysics, 39, 427-436.

Lohman, D. F. (1996). Spatial ability and g. Human Abilities: Their nature and Measurement, 97, 116.
Maeda, Y. ve Yoon, S. Y. (2013). A meta-analysis on gender differences in mental rotation ability measured by the Purdue spatial visualization tests: Visualization of rotations (PSVT: R). Educational Psychology Review, 25(1), 69-94.

McGee, M. G. (1979). Human spatial abilities: Psychometric studies and environmental, genetic, hormonal, and neurological influences. Psychological bulletin, 86(5), 889.

Moreau, D. (2012). The role of motor processes in three-dimensional mental rotation: Shaping cognitive processing via sensorimotor experience. Learning and Individual Differences, 22(3), 354359.

Neubauer, A. C., Bergner, S., \& Schatz, M. (2010). Twovs. three-dimensional presentation of mental rotation tasks: Sex differences and effects of training on performance and brain activation. Intelligence, 38(5), 529-539.

Olkun, S., Altun, A. ve N. Üniversitesi. (2003). İlköğretim öğrencilerinin bilgisayar deneyimleri ile uzamsal düşünme ve geometri başarıları arasındaki ilişki. The Turkish Online Journal of Educational Technology, 2(4), 86-91.

Parsons, T. D., Courtney, C. G., Dawson, M. E., Rizzo, A. A. ve Arizmendi, B. J. (2013, Temmuz). Visuospatial processing and learning effects in virtual reality based mental rotation and navigational tasks. International Conference on Engineering Psychology and Cognitive Ergonomics (pp. 75-83). Springer, Berlin, Heidelberg.

Passini, R. (1984). Spatial representations, a wayfinding perspective. Journal of Environmental Psychology, 4(2), 153-164.

Pazzaglia, F. ve De Beni, R. (2001). Strategies of processing spatial information in survey and landmark-centred individuals. European Journal of Cognitive Psychology, 13, 493-508.

Pazzaglia, F. ve De Beni, R. (2006). Are people with high and low mental representation abilities differently susceptible to the alignment effect? Perception, 35, 369-383.

Pearson, D. G., Deeprose, C., Wallace-Hadrill, S. M., Heyes, S. B. ve Holmes, E. A. (2013). Assessing mental imagery in clinical psychology: A review of imagery measures and a guiding framework. Clinical Psychology Review, 33(1), 1-23.

Pellegrino, J. W., Alderton, D. L. ve Shute, V. J. (1984). Understanding spatial ability. Educational Psychologist, 19(4), 239-253.

Peters, M. (2005). Sex differences and the factor of time in solving Vandenberg and Kuse mental rotation problems. Brain and Cognition, 57, 176-184. 
Pezaris, E. ve Casey, M. B. (1991). Girls who use "masculine" problem-solving strategies on a spatial task: Proposed genetic and environmental factors. Brain and Cognition, 171, 1-22.

Quinn, P. C. ve Liben, L. S. (2008). A sex difference in mental rotation in young infants. Psychological Science, 19(11), 1067-1070.

Sharps, M. J., Price, J. L. ve Williams, J. K. (1994). Spatial Cognition and Gender Instructional and Stimulus Influences on Mental Image Rotation Performance. Psychology of Women Quarterly, 183, 413-425.

Shepard, R. N. ve Metzler, J. (1971). Mental rotation of three-dimensional objects. Science, 171, 701-703.

Tarr, M. J. ve Pinker, S. (1990). When does human object recognition use a viewer-centered reference frame?. Psychological Science, 1(4), 253-256.

Taylor, H. A. ve Tversky, B. (1996). Perspective in spatial descriptions. Journal of Memory and Language, 35(3), 371-391.

Tottenham, L. S., Saucier, D., Elias, L. ve Gutwin, C. (2003). Female advantage for spatial location memory in both static and dynamic environments. Brain and Cognition, 53(2), 381-383.

Turgut, M. (2007). Investigation of 6., 7. and 8. grade students' spatial ability. Unpublished master's thesis. Izmir, Turkey: Dokuz Eylul University.

Turgut, S., Erden, G. ve Karakaş, S. (2010). The profiles of Specific Learning Disability (SLD), attention deficit hyperactivity disorder comorbid with SLD and control group through the SLD battery. Turkish Journal of Child and Adolescent Mental Health, 17(1), 13-26.

Uttal, D. H. ve Cohen, C. A. (2012). Spatial thinking and STEM education: When, why and how. Psychology of Learning and Motivation, 57, 147-181.

Vandenberg, S. ve Kuse, A. R. (1978). Mental rotations: A group test of three dimensional spatial visualization. Perceptual and Motor Skills, 47, 599-604.

Vasilyeva, M. ve Lourenco, S. F. (2012). Development of spatial cognition. Wiley Interdisciplinary Reviews: Cognitive Science, 3(3), 349-362.

Voyer, D. ve Bryden, M. P. (1990). Gender, level of spatial ability, and lateralization of mental rotation. Brain and Cognition, 13, 18-29.

Voyer, D., Voyer, S. ve Bryden, M. P. (1995). Magnitude of sex differences in spatial abilities: a meta-analysis and consideration of critical variables. Psychological Bulletin, 117, 250-270.

Voyer, D., Voyer, S. D. ve Saint-Aubin, J. (2017). Sex differences in visual-spatial working memory: a meta-analysis. Psychonomic Bulletin \& Review, 24(2), 307-334.
Wai, J., Lubinski, D. ve Benbow, C. P. (2009). Spatial ability for STEM domains: Aligning over 50 years of cumulative psychological knowledge solidifies its importance. Journal of Educational Psycho$\log y, 101(4), 817$.

Yuille, J. C. ve Steiger, J. H. (1982). Nonholistic processing in mental rotation: Some suggestive evidence. Perception \& Psychophysics, 31, 201-20. 


\title{
Summary \\ Spatial Representation: The Effect of Spatial Thinking on Mental Rotation Performance
}

\author{
A. Reyyan Bilge ${ }^{1}$ \\ İstanbul Şehir University \\ İstanbul Medipol University
}

Spatial processing, by definition, extends from very trivial tasks such as moving without bumping into furniture to reading a map or driving. Knowing the internal representations of a given structure or an environment is also within the realm of spatial cognition. In order to carry out these tasks we continuously process spatial information and create spatial mental models (Taylor \& Tvesky, 1996) upon which we rely on for later use. Factors such as our preferences, representations, and strategies were suggested to affect the way we think about space. Understanding the individual differences, especially frequently reported sex difference, is important for spatial processing. The current study, based on the previous work (Bilge \& Taylor, 2017), investigated the underlying reasons for possible performance difference in spatial tasks by holding the gender variable constant. By measuring spatial ability and assessing spatial thinking style, the study aimed to show the variance even within a same-sex group suggesting spatial representation to be an alternative factor to account for the difference in MR performance.

One way to investigate how people process spatial information is people's spatial thinking style. From very early on we learn to think about space in certain ways: how we prefer to receive spatial information and how we mentally represent this knowledge, a term we coined as habitual spatial thinking (Bilge \& Taylor, 2017). Information could be processed at a more global level via survey perspective or at more local level via route or landmark perspective. Pazzaglia and De Beni (2001) designed a questionnaire to categorize people as having survey-, and landmark-centered representations. The resultant mental representations are also related to performance on spatial tasks. People with a tendency to create survey-representations scored better on a mental rotation test compared to individuals who habitually took a landmark-centered approach (Pazzaglia \& De Beni, 2001; 2006). Thus, one's spatial representation (survey or landmark) has major appears to have an impact on spatial processing.

Another way to investigate spatial processing is through tasks that measure spatial skills. A small-scale task such as Mental Rotation (MR) (Shepard \& Metzler, 1971; Vandenberg \& Kuse, 1978). MR is one of the most commonly used tests to assess spatial ability. In classic MR experiments (Shepard and Metzler, 1971), participants decide whether two figures are the same or mirror images of one another. To solve this problem, they need to rotate one of the figures to match with the other one (Gardony, Taylor, \& Brunye, 2014). The pair could be rotated versions of one another, which would need a "same" judgment, or one of the figures could be flipped creating mirror reflections of the pair, which would require a "different" judgment. The most common finding is the decreased rotation rate and accuracy ratio with the increase in angular disparity between the figures. The other common finding is men outperforming women in rotation (Linn \& Petersen, 1985; Voyer, Voyer, \& Bryden, 1995). In reality this male advantage may be more complex. Some studies have found no sex difference (Butler et al., 2006; Heil \& Jansen-Osmann 2008; Jordan et al., 2002) and in other studies women were faster. Variability in MR sex differences suggests that other factors may contribute to MR performance.

Sex difference was suggested to stem from the way people solve these problems; applying different strategies (Kail, Carter, \& Pellegrino, 1979). Two MR strategies have been proposed basing on the pattern of rotation performance: holistic and piecemeal. While mentally rotating 3D figures, men seem to rotate the figures as a whole, applying a holistic strategy, and women were suggested to use a piecemeal strategy where they divide the figure into its pieces, rotate each piece in their minds, then put the resultant pieces back together. This, of course, is a more tedious process and is suggested to be the reason for reported sex difference. However, to en-

Address for Correspondence: Assoc. Prof. A. Reyyan Bilge, Medipol University, Humanities and Social Sciences, Department of Psychology, Kavacık South Campus, Göztepe Mah. Atatürk Cad. No: 40 / 16, 34815 Beykoz / İstanbul

E-mail: reyyan.bilge@medipol.edu.tr 
gage the use of piecemeal strategy, cut figures were used in this research following earlier work (Bilge \& Taylor, 2017; Boone \& Hegarty, 2017). This is a novel approach to examine the strategy used in MR task.

\section{Current research}

Cognitive strategies used in MR problems were suggested to account for the variance in performance. Holistic strategy users rotate 3-dimensional figures as a whole whereas piecemeal strategy users rotate in pieces. However, there is not a direct link between sex and strategies, as suggested. Moreover, great variability in MR performance points to other possible contributing factors. Previous work found spatial thinking style (e.g., mental representation) to be one of those factors (Bilge \& Taylor, 2017). The current study, investigated the effect of different mental representations on MR performance while keeping sex constant. If within an all-woman sample, different mental representations and strategies are found to affect MR performance it would suggest a link between spatial thinking style and MR.

\section{Method}

\section{Participants}

Sixty-one women undergraduates $(M=21.2, S D=$ 2.6) from Istanbul Sehir University (28 survey, 33 landmark representations) were recruited in this experiment.

\section{Materials}

MR Stimuli were 3-D block figures. They were presented in pairs that were defined by two factors, figure presentation (whole, cut) and angular difference (0-, 30-, 60-, 90-, 120-, 150-, and 180- degrees). These 3D block figures comprised the whole figures. Cut figures were created dividing the whole figures into two parts.

Mental Representation Questionnaire (Pazzaglia \& De Beni, 2001) examined spatial processing habits by asking 17 questions on a 5-Likert scale. The statements asked participants to rate their answers from 1 to 5,1 indicating "not agree at all" and 5 "agree very much". Cumulative scores allowed participants to be categorized as creating more survey-representations, or landmark-representations when encountering larger scale environmental information.

Santa Barbara Sense of Direction Scale (Hegarty et al., 2002) was used to assess one's sense of direction through self-report. There were 15 statements, which needed to be rated on a 7-Likert-type scale. Participants chose from "1" (totally agree) to "7" (totally disagree) and their total scores were calculated to identify them as having high or low sense of direction.

\section{Procedure}

All the participants were presented with a block of whole figures and a block of cut figures, in counterbalanced order. They then completed the questionnaires, through which they were categorized as having surveyor landmark-representations.

\section{Results}

A 2 X 7 X 2 repeated-measure ANOVA was conducted, where Rotation Degree $\left(0^{\circ}\right.$ - to $\left.180^{\circ}\right)$ and Figure Presentation (whole and cut) were within-participant variables and Spatial Representation (survey and landmark) was a between-participant variable. Dependent variables were reaction time (RT) and accuracy rate.

There was a main effect of Rotation Degree for RT data, $F(2.59,152.59)=82.8, p<.001, \eta \mathrm{P} 2=.584$. Furthermore, Rotation Degree showed a main effect for accuracy data, $F(3.66,215.78)=33.07, p<.001, \eta \mathrm{P} 2$ $=.359$ supporting the Angular Disparity Effect. Participants responded slower and less accurately as the degree of rotation between the figure pairs increased.

There was an interaction between Rotation Degree and Spatial Representation, $F(6,354)=3.53, p=.021$, $\eta \mathrm{P} 2=.057$. With increasing angular disparity between the figures, participants who relied more on survey-representations performed faster while the smaller angular disparities did not show that difference between surveyand landmark users.

An interaction between Rotation Degree and Figure Presentation was also observed, for both RT $(F(5.45$, $321.55)=2.59, p=.022, \eta \mathrm{P} 2=.042)$ and accuracy data $(F(5.54,326.86)=6.43, p<.001, \eta \mathrm{P} 2=.098)$. The pattern for rotation of whole and cut figures flipped with increasing angular disparity. For relatively smaller disparity, cut figures seemed to be rotated more accurately yet this changed with greater disparity.

\section{Discussion}

The current research supported and extended the previous literature on MR. Findings supported the literature by showing the angular disparity effect. Participants rotated 3D images in their minds more slowly and less accurately as the angular disparity between the figures increased. The study also extended the literature by introducing strategy-consistent stimuli (cut versions to engage piecemeal processing and whole figures for using holistic strategy) to an all-women population. If the women showed variance in their performance, then sex would not be the factor to explain the said difference since it was held constant. Therefore, the findings suggested that there could and should be other factors to 
account for these individual differences such as spatial thinking style.

Another factor that was found to influence MR performance in some form was the way we represent the environment in our minds (spatial representation). When encountered with larger-scale environments, people create spatial mental models (Taylor \& Tversky, 1996) and represent space either with a survey or landmark perspective (Easton \& Sholl, 1995; Pazzaglia \& De Beni, 2001). In the literature, women were also suggested to use a piecemeal strategy with MR and to rely more on landmark representations. However, the current study sample consisted of women who created landmark or survey representations, both. Furthermore, the results of the current study mimicked the literature (Bilge \& Taylor, 2017) by showing varying MR performances by participants with survey and landmark representations, observed with the increasing angular disparity. Again, MR performances differed while rotating whole and cut figures, especially over degrees of rotation. The combination of these factors and examining their joint effects is new to the literature. Furthermore, drawing a possible link between how we come to think about larger-scale environments and how we solve smaller-scale MR problems would be influential for future of spatial cognition. 